\title{
GOVERNMENT POLICIES STRATEGY IN DEALING WITH THE COVID-19 OUTBREAK: LESSONS FROM TAIWAN'S EXPERIENCE
}

\author{
Helen Dian Fridayani \\ Graduate Institute of Political Economy, National Cheng Kung University, Taiwan \\ Helendianf9@gmail.com/u18087030@gs.ncku.edu.tw
}

\begin{abstract}
This article contributes to the field of public policy and provides a concrete figure of how the government's policy strategy in combating the Covid-19 epidemic. Taiwan was very much situated to respond rapidly and viably to the Covid-19 outbreak. Taiwan's involvement in SARS in 2003 helped drive the government to respond quickly to the rising emergency. Taiwan is not a member of the WHO, but the strategies carried out by the Taiwanese government can provide lessons and examples for other countries. The method used in this research are observation and literature study, looking for theoretical references that are relevant to cases or problems regarding the handling of the covid-19 outbreak in Taiwan. The aftereffects of this study demonstrate that, Taiwan is not just a guide of majority rule government, yet in addition living evidence that control of a rising infection can be accomplished through science, innovation, and democratic governance. No radical despotic measures are required. The government responded rapidly and conclusively in January, by establishing early travel limitations, turning out testing, and stating control of clinical stockpile lines. Taiwan additionally perceived the potential for human-to-human transmission before China or the WHO did. Through these measures, Taiwan has had the option to maintain a strategic distance from the kind of clearing lockdowns actualized the world over.
\end{abstract}

Keywords: Covid-19 Outbreak, Government Policy, Strategy, Taiwan's Experience.

Received 23 April 2020 Accepted 7 October 2020

\section{INTRODUCTION}

On December 31, 2019, an outbreak of respiratory sickness later ended up being brought about by a novel coronavirus, authoritatively named Coronavirus Disease 2019 (Covid-19), was informed first in Wuhan, a city of Hubei area, People's Republic of China (PRC). COVID-19 quickly spreads in China and to around the world and been declared a pandemic by the World Health Organization (Cheng et al., 2020). The number of world cases to date has reached $2,185,938$ and the death rate has reached $146,969(6.7 \%)$ of the total cases (April, $16^{\text {th }}$ worldmatters.com, 2020). Covid-19 is a genuinely worldwide issue, contacting each edge of the world. From the immediate wellbeing effect on economy, social, and political consequences, the pandemic can possibly reshape nations over the globe even those yet to report any affirmed cases. However, while the issues are comparable, the effects on and reactions from every nation are extraordinary (Wu, Chen, \& Chan, 2019).

As a result of this outbreak, each nation needs to act quickly to plan, react, and recoup. The underlying moderate reaction in nations, for example, the UK, the USA, and Sweden presently looks progressively ineffectively judged. As pioneers scramble to gain indicative tests, individual defensive gear, and ventilators for overpowered emergency clinics, there is a developing feeling of outrage (WHO, 2020b). The Covid-19 outbreak influences all fragments of the populace and is especially negative to individuals from those social groups in the most 
powerless circumstances, keeps on influencing populaces, including individuals living in neediness circumstances, older people, people with incapacities, youth, and indigenous people groups. Early proof shows that that the wellbeing and monetary effects of the infection are being borne excessively by needy individuals (WHO, 2020). For instance, vagrants, since they might be not able to securely shield set up, are profoundly presented to the threat of the infection. Individuals without access to running water, evacuees, vagrants, or dislodged people likewise remain to experience the ill effects of the pandemic and its consequence regardless of whether because of restricted development, less work openings, expanded xenophobia and so on (Wu et al., 2019). The interwoven of unsafe beginning responses from numerous pioneers, from disavowal and lost positive thinking, to detached acknowledgment of enormous scope passing, was defended by words, for example, exceptional. A few Asian governments have been touted for their generally effective control of the primary flood of the pandemic: Singapore, South Korea, and Hong Kong (Mayr et al., 2020). What's forgotten about in the conversation is the thing that a little Pacific Ocean island the size of Maryland has accomplished in battling COVID-19, Taiwan. The Covid-19 flare-up keeps on spreading the world over. While governments are endeavoring to take successful counteraction measures, Taiwan is being adulated by remote media for its speedy response and viable anticipation measures (Lin, 2020). Taiwan has fever affirmed Covid-19 cases than neighboring nations, for example, South Korea and Japan. Nations confronting a quick increment of affirmed cases are experiencing open frenzy, yet additionally from a lack of veils (Hui, 2020).

Taiwan had learned to deal with a pandemic from the SARS case in 2003 (Nelson, 2020). At that time, this country together with Hong Kong and southeastern China, became the location most affected by SARS (Sui, 2020). At that time, more than 150 thousand people were quarantined on the island which is located 180 kilometers from the southeast coast of China. As many as 180 people died due to SARS at the time (Taiwan Centers for Disease Control, 2020). Reflecting on SARS, several countries in Asia have indeed become more prepared in facing COVID-19. The government and the public know better what they have to do such as tightening the rules at the border and requiring the use of masks (Schafer, 2020).

On 21 January, the primary case in Taiwan was affirmed in a 50-year-elderly person who had recently come back to Taoyuan International Airport from her showing work in Wuhan (www.cdc.gov.tw., April, 2020). She provided details regarding her own drive and was hospitalized without formal household passage. The main residential case was analyzed in Taiwan on 28 January (www.cdc.gov.tw., April, 2020). The principal demise in Taiwan was affirmed on 16 February including a man in his 60s who had Hepatitis B and diabetes (Taiwan Centers for Disease Control, 2020). Experts from the beginning had predicted that Taiwan as a country of 23 million people would be greatly affected by Covid-19. The fact is that, although 850,000 people live in Mainland China, the country which has not been recognized by the United Nations to date has only 395 cases confirmed with six deaths (Taiwan Centers for Disease Control, 2020). The number is considered very low if you look at the proximity of the country with China and the frequency of flights between countries. Therefore, Taiwan is recognized by the world as a country that is able to control the spread of the Covid-19 virus well, although it does not enter into the world health organization. This paper will discuss further about how the policy strategy adopted by the government to handle and control the spread of the Covid-19 virus in Taiwan.

\section{LITERATURE REVIEW}

With the first case in Taiwan, the government incorporated assets across government offices, fortified execution of isolate measures at universal including cross-waterway air terminals and 
ports, strengthened hazard correspondence with people in general and open mindfulness about the sickness, guaranteeing the arrangement of pharmaceutical and clinical supplies to forestall the event of phony news concerning cover deficiencies and costs gouging and diminish open frenzy, plan and lead drills for emergency clinic disease control at human services offices so as to limit the effect of the episode in Taiwan, handle the dangers and difficulties presented by the flare-up, and guarantee the wellbeing of the Taiwanese open. Etymologically, public policy starts with a need, benefit and world while (Mackay, n.d.). It can be from, for and by the state, private sector, civil society that can propose and propose to be taken into consideration in decision making called policy input. However, the policy process that is carried out is sometimes not in line with the expectations of the existing inputs. Many policies are not in line with the principles of justice, goodness and expediency (Oni, 2019).

These were measures, embraced by delegates of governments, laborers' and businesses' associations, give a human-focused way to deal with development and improvement, including by activating strategy switches that both animate request and secure specialists and ventures. According to (International Labour Organization, 2020) Policy responses should concentrate on two prompt objectives: Health security measures and economic support. According to (WHO, 2020) there are several indicators to take policy to prevent and handing the Covid-19 which are Country-level coordination, planning, and monitoring; Risk communication and community engagement; Surveillance, rapid-response teams, and case investigation; Points of entry; National laboratories; Infection prevention and control; Case management; Operations support and logistics.

Public policy consists of various elements, so it needs to be seen from various aspects and considerations to produce a good, appropriate, effective and efficient and fair policy (Kevin B. Smith \& Christopher W. Larimer, 2009). Social, cultural, political, and economic aspects must be a fundamental study in public policy. So that it does not cause friction that leads to conflict or policy that causes noise in the community. Also provides an understanding analysis of the process of making good and applicable policies, namely the theoretic system (John, 2018). The system theory emphasizes that public policies must have inputs (individuals or community groups, governments or others) (Hevia \& Neumeyer, 2020). From the existing input will cause demand (opponents) and support (supporters) or in other languages that in making public policies there must be pros (support) there must also be cons (reject) of the policy (Mackay, n.d.). From demand and support, it becomes an in-depth analysis that must be carried out to see the benefits and success aspects of the policy to be taken (John, 2018). The interest of the community in public policy is first and foremost must prioritize other interests (Djalante, Shaw, \& Dewit, 2020).

Policies adopted by the government to deal with Covid-19 are various kinds, for example, look into led by Fisher (2020) in theconversation.com which says that Singapore's reaction to the coronavirus has been held up by numerous individuals around the globe as a model and its contamination rate is much more slow than the remainder of the world. What can be discovered from Singapore strategy is following contacts and testing generously, keeping individuals who test constructive in clinics, solid and ordinary correspondence on what individuals can do to limit the hazard, not going into lockdown dependent on dread, and sorted out initiative (Fisher, Dale, 2020). Korea has since actualized a few measures to viably "straighten the bend" and give auspicious clinical consideration to the contaminated. Countries around the globe are confronting a comparable ascent in diseases while their primary care physicians and clinical staff chance introduction without appropriate hardware and apparatus. As per Ash, J. Michel (2020) the exercises from Korea are secure doctors and clinical staff, forestall further disease 
to residents at emergency clinics, spread all covid-19 clinical costs, e-government, it framework, open part development, culture of wearing facemasks, straightforwardness, exercise leadership.

Other example based on WHO report (2020) analyze that China's methodology included early lockdown and exacting isolate; extreme limitations on worldwide and local travel; utilization of wellbeing QR codes for authorizations to move around a city; visit building and road disinfection; testing, conceding and treatment everything being equal; and disconnecting suspected cases are the best practice in war with Covid-19. The benefits of these were collaboration (regardless of whether upheld), unburdening and fast increment in the limit of the wellbeing framework (ex. with 'alarm working' of medical clinics). These early and intense measures assisted with postponing the spread of the infection from Hubei to different territories. An investigation on flexibility of frameworks in Hong Kong and Japan has demonstrated that regulation procedures there appear to be so far to have forestalled across the board network transmission (WHO Report, 2020). In these two nations reconnaissance frameworks were straightened out to distinguish potential cases and their contacts, indicative tests were grown right off the bat, and research center testing limit was expanded. Various methodologies were utilized to specifically control voyagers entering these areas, from incomplete passage limitations (Japan) to obligatory 14-day isolate (Hong Kong) of nonnearby guests (Wu et al., 2019). Intragovernmental coordination was improved dependent on the past encounters during SARS and H5N1 flare-up (Nadeem, 2020). In all areas, every single direct expense for treating patients are secured by the administrations, proper preparing and adherence to contamination avoidance and control measures are rehearsed in medical clinics.

\section{RESEARCH METHOD}

The research method used is a qualitative approach to data collection using observation and literature studies. observation method is seeing and listening to events or actions carried out by people observed, then record the results of observations with notes or other tools (Creswell, 2010). Other, what is meant by library research is research conducted based only on written works, including research results both those that have been and that have not been published (Embun, 2012). The data needed in research can be obtained from library sources or documents. According to (Zed, 2014), in library research, library search is not only for the initial steps of preparing a research framework but also at the same time utilizing library resources to obtain research data. Researchers tried to collect data related to Covid-19 management conducted by the Taiwan government both in policy and strategy. From the methods used, a framework can be drawn that can describe Taiwan's strategy in combating the Covid-19 outbreak.

\section{FINDING AND DISCUSSION}

Many countries in the world have so far fought against Covid-19, a virus from Hubei, Wuhan, China. Covid-19 has quickly transformed into a remarkable wellbeing, economic and geopolitical emergency (Djalante et al., 2020). It definitely underscores the basic of quickening the joining of different worldwide arrangement structures, not least those at the focal point of the 2030 Agenda. Preceding the development of COVID-19, the UN Secretary General had situated 2020 as the "super year" for activity on maintainability (UN, 2020).

As Covid-19 transmission has progressed all inclusive, the essential focal point of most nations has been the quick distinguishing proof, testing and treatment of patients with genuine and extreme Covid-19, and the shielding of people at the most noteworthy danger of poor results (Nelson, 2020). Less have set up measures for those with gentle illness, or contacts of cases (Mayr et al., 2020). Nations must do all that they can to prevent cases from turning out to be 
bunches and groups from turning out to be dangerous outbreak. They should set up the capacities with respect to testing and conclusion, separation, contact following and isolate; they should connect with everybody in the response.

Each state strategy has a urgent part to play in meeting the worldwide destinations, and must, at the very least, set out the reason for a) coordination of the national and subnational reaction; b) commitment and activation of influenced and in danger networks; c) execution of setting suitable general wellbeing measures to slow transmission and control inconsistent cases; d) arrangement of the wellbeing framework to diminish Covid-19-related mortality, keep up fundamental wellbeing administrations, and secure wellbeing laborers, and e) possibility intending to guarantee congruity of basic open capacities and administrations (WHO, 2020). the number of world cases to date has reached 2,185,938 and the death rate has reached 146,969 $(6.7 \%)$ of the total cases (April, 16th worldmatters.com, 2020). See the picture below:
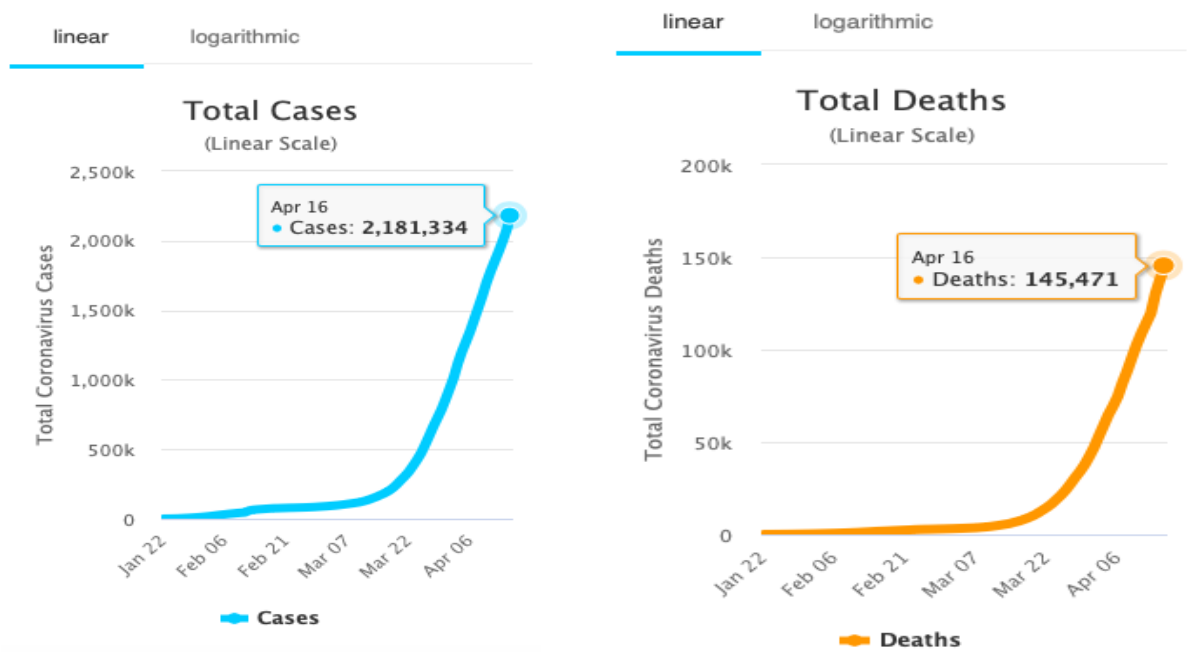

Figure 1. Data on Positive and Mortality in Worldwide due to Covid-19 Source: Worldmeter Info, April, 16 ${ }^{\text {th }}, 2020$.

Looking at the data above, as the command from WHO each nation must keep on actualizing National Action Plans dependent on a whole- of- society approach and a practical examination of what is attainable to accomplish first in quite a while of hindering transmission and diminishing mortality, and in this manner regarding supporting low level transmission while society and economic movement resumes. Plans must be adaptable enough to respond to quickly changing epidemiological circumstances in various pieces of the nation, and consider the neighborhood settings and abilities to react. Several cases in the world have been described in the literature review section. Several countries have demonstrated success in combating the Covid-19 outbreak. This section will describe the success of Taiwan in combating the Covid19 outbreak.

\section{Taiwan Story on Fight with Covid-19 Outbreak}

On 21 January, the principal case in Taiwan was affirmed in a 50-year-elderly person who had recently come back to Taoyuan International Airport from her showing work in Wuhan(Taiwan Centers for Disease Control, 2020). She gave her very own account activity and was hospitalized without formal household entry. The main residential case was analyzed in Taiwan on 28 January. The primary demise in Taiwan was affirmed on 16 February including a man 
in his 60s who had Hepatitis B and diabetes. A lady in Taiwan was accounted for to have tried constructive for novel coronavirus on 19 February 2020, however she had not gone outside of Taiwan for two years (Nelson, 2020). Five new instances of coronavirus were accounted for in Taiwan on 29 February 2020, four of which denoted the primary transmission of the ailment in a medical clinic setting. Taiwan's fiftieth instance of coronavirus was affirmed on 13 March 2020, an American ostracize who facilitated four United States residents at his home in Taiwan. The following day, three new instances of coronavirus were affirmed to have been imported from Europe (Taiwan Centers for Disease Control, 2020). A Taiwanese national on board the Diamond Princess tried constructive on 6 February. As of 19 February, five Taiwanese nationals on board the boat tried positive (Yang, 2020). Two Taiwanese who became sick on the Diamond Princess were released from Japanese emergency clinics in February 2020. The nineteen other Taiwanese travelers on the Diamond Princess were isolated in Taiwan until 7 March 2020 (C. Huang et al., 2020). All tried antagonistic for coronavirus, and were released. The record case for coronavirus in Taiwan recuperated from the infection and was released from emergency clinic on 6 February 2020. Approximately seven days after the fact, a second Taiwanese national, the tenth instance of coronavirus, had likewise recovered. As of 16 April 2020, 155 individuals have recouped from coronavirus in Taiwan. On 15 March, Taiwan reported six new cases, all imported. Taiwan's wellbeing priest has prompted individuals to stay in Taiwan and keep away from travel. On 20 March 2020, Taiwan revealed 27 new cases, the most elevated single-day increase. The subsequent passing connected to coronavirus in Taiwan was declared on 20 March, and included a man in his 80s, who had no ongoing travel history, however had hypertension, diabetes and depended on kidney dialysis. The demise of a guide who had driven visits to Austria and the Czech Republic was accounted for on 29 March. The following day, two Taiwanese nationals who had made a trip to Spain were accounted for to have kicked the bucket of coronavirus. A Taiwanese man who had visited Egypt in March passed on of coronavirus on 9 April. Starting at 13 April, there are 395 affirmed cases, including six deaths. Among the affirmed cases is a Taiwanese man in his 50s who was fined NT\$300,000 for inability to report his side effects and endeavoring to disguise his consequent exercises, prompting a potential sullying episode at a dance hall in Kaohsiung (Taiwan Centers for Disease Control, 2020).

\section{Taiwan Strategy on Fight Covid-19 Outbreak}

Taiwan has been all around praised as a model for its Covid-19 reaction, and in light of current circumstances: in spite of its closeness to and visit cross-fringe associations with China, where the flare-up started, Taiwan has restricted its cases to only 395 as of April 16, with just six passing (Sui, 2020). That is on the grounds that the government responded rapidly and unequivocally since January. Taiwan was very situated to respond rapidly and successfully to the Covid-19 flare-up. Taiwan's involvement in SARS in 2003 helped drive the legislature to respond quickly to the rising emergency, arranging the obscure illness as extreme special infectious pneumonia as ahead of schedule as January 15, preceding later receiving the name Covid-19 (Husnayain, Fuad, \& Su, 2020). Furthermore, Taiwan has a 99.9\% national medical coverage inclusion rate and has been assessed as the world's best framework by the Global Health Care Index (Cheng et al., 2020). Early mediation, an adaptable order structure, a complete pandemic avoidance procedure, incorporated clinical huge information, and proactive data divulgence permitted Taiwan which at its nearest point is just eighty-one miles (130 kilometers) away from China and has an extremely high populace thickness to record just a couple of affirmed cases as of late (Yang, 2020). Prevention in Taiwan split into two, before and after the first case reported of the Covid-19 outbreak entered Taiwan. Prior to first case reported, Taiwan Centers for Disease Control (CDC) actualized assessment measures for 
inbound departures from Wuhan, China in light of reports of an unidentified outbreak $(\mathrm{Pu}$, 2020). The travelers of every single such flight were investigated by wellbeing authorities before disembarking. A six-year-old traveler who moved in Wuhan and built up a fever was firmly checked by CDC (Taiwan Centers for Disease Control, 2020). At this time, there were asserted to be 27 instances of the new pneumonia in Wuhan (Sui, 2020). The government esteemed the hazard presented by the flare-up adequate to initiate the Central Epidemic Command Center. Originally settled as a level 3 government entity that has composed government reactions across territories remembering coordination for residents for the Diamond Princess, sanitization of open spaces around schools, and giving day by day briefings with the Minister of Health and Welfare (W. Huang et al., 2020). Afterward, since the first case reported in Taiwan, the government declared a brief restriction on the fare of face covers for a month on 24 January to make sure about an inventory of covers for its own citizens. The boycott was broadened twice; on 13 February until the finish of April, and on 13 April until the end of June (Jennifer, 2020). In combating the Covid-19 outbreak the Taiwan government did not make the last option chosen by some countries as the best alternative, lockdown. The government itself is still able to tackle the Covid-19 outbreak by means of restriction, mitigation, and emergency response so lockdown is not needed in Taiwan. If described in Taiwan's position with the graph is as follows.

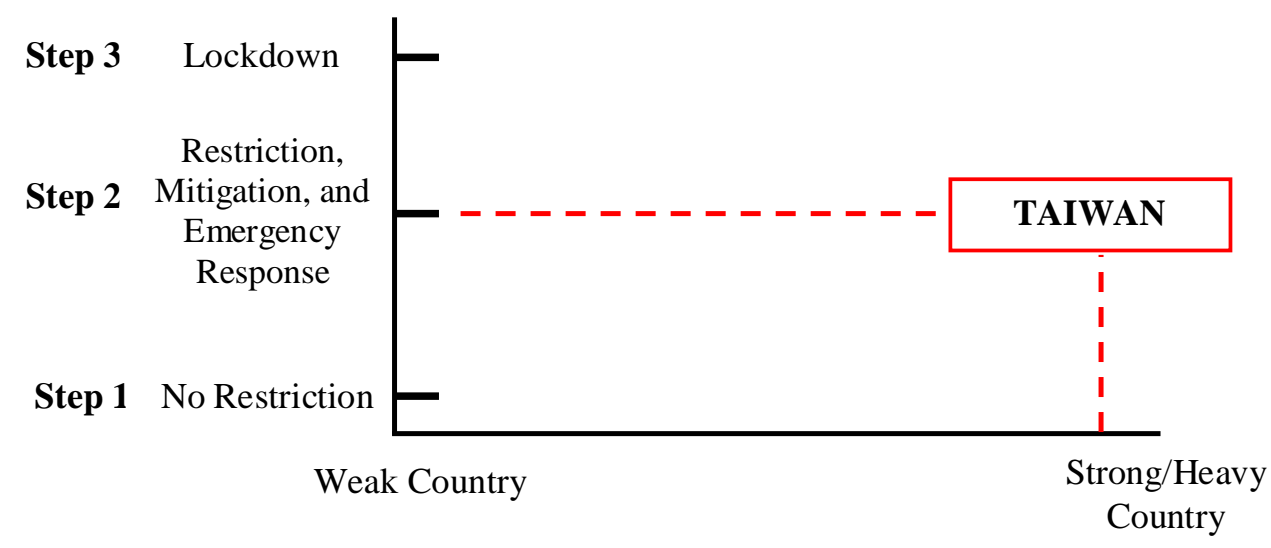

Source: Author Framework.

Figure 2. Three Step in Country Managing Covid-19 Outbreak

Observed in various countries around the world, it can be seen that in handling this pandemic there are three stages, to be specific the primary stage there is no denial or limitations by any stretch of the imagination, implying that the nation despite everything thinks about no threat, simple, and simply loosen up this pandemic. Then second, having restrictions, mitigation, and emergency response Judging from the graph above, Taiwan is in step 2 with restriction, mitigation, and emergency response. The country is still able to deal with a pandemic without lockdown. Lockdown is a condition where the country has no other choice and is the best choice. In some countries such as China, the United States, the Philippines, Britain, India, Malaysia, Italy, and even South Africa choose lockdown because it is the best choice so that the transmission of the virus does not spread widely in their countries (Wu et al., 2019). A lockdown policy means locking all access in and out of the country or region to prevent the spread of Covid-19 (Lin, 2020). The community was arranged in such a way so as not to roam around and gather in public places. However, lockdown also affects the economy in a country, for example consumption behavior will change. Lockdown will cause a panic buying phenomenon in the community and this will disrupt the smooth distribution of goods and 
services (Mayr et al., 2020). The Government of Taiwan applies several policies in health such as:

1) Testing capacity: A national testing network has been established to improve Taiwan's testing capacity. The strategy allows the maximum testing capacity per day to reach 3,800 specimen tests, and Covid-19 testing to be conducted in different areas to reduce wait time for test results.

2) Community surveillance: A community specimen surveillance program and protocols of different levels of care for patients have been implemented to enhance community surveillance network.

3) Expanding hospital capacity: Plans for healthcare preparedness in the designated emergency response hospitals and wards have been implemented, in four phases, to improve national health care capacity.

4) Taking inventory of clinical beds: Health agencies constantly keep track of available beds for severe cases of COVID-19.

5) Requisitioning facilities: The strategy aims to increase the number of designated sites for group quarantine.

6) Patient diversion and transfers: The principles for the diversion, ward segregation and transport of COVID-19 patients have been made to ensure appropriate care is given to patients.

Other policies that taken by Taiwan government, in accordance with Transmittable Disease Control Act (傳染病防治法), an open and straightforward scourge data stage was built up through the Focal Epidemic Situation Command Center (中央流行疫情指揮中心). A day by day public interview was held to clarify the pestilence circumstance (Sui, 2020). At the same time refreshes originated from pertinent government offices, clinical foundations, and private internet-based life accounts. Likewise, Taiwan's administration regularly centers around pestilence counteraction for fakers (防疫懶人包) straightforward realistic depictions to share information on pandemic avoidance across enormous systems, so as to step by step dispersal of right direction on anticipation and control among the general population. An additional, Taiwan has a strong data and communication infrastructure (Pu, 2020). During the pandemic, the Taiwanese government effectively helped out private media organizations to routinely communicate essential preventive information, for example, "washing hands and wearing masks" on TV and radio broadcasts. Moreover, Taiwan itself applies a regulation on the purchase of masks. Per Week is limited to only 3, then 5, then finally each person can buy 9 masks. This is due to anticipate the scarcity of masks in Taiwan during Covid-19.

Furthermore, Taiwan utilizes the national medical coverage database and coordinated it with the migration and customs database to start the formation of huge information for examination. This database produced constant alarms (Jhang, 2020). It can follow travel history and clinical manifestations to perceive the conceivable Covid-19 casualty. So as to forestall the transmission of deception and disinformation, Taiwan has set up the "Taiwan FactCheck Center," and every office right now has an "Image Engineering group" (迷因工程團隊) (Hui, 2020). At the point when it finds deception or disinformation on the web, the group will confirm it inside an hour and explain it to the open right away. These measures can forestall pointless frenzy and tension during the pestilence anticipation period.

Taiwan is not included in the WHO organization, Taiwan is claimed by China as part of its territory, and China prevents Taiwan from participating in many international organizations. The lack of information related to Covid-19 received by the Taiwan government forced them to formulate policies independently to prevent the corona virus from spreading widely in the 
country regardless of what the WHO recommended. Rapid response and transparency of the Taiwan government in informing the latest developments of the Covid-19 outbreak became one of the triggers of Taiwan's success in preventing Covid-19 transmission. The government opened information about road routes and locations that have passed positive Covid-19 patients in the last few days. The information that is opened is really just a matter of the route of the road and the location, not the identity of the patient. This is done so that people who have been in the same location and hour as the patient or have contact can be more introspective and immediately go to the hospital if they feel there are symptoms of Covid-19, so as to minimize the risk of wider infections. The simply categories policy according the findings in Taiwan strategy in combating Covid-19 outbreak as follow:

Taiwan's Strategy

Early Prepareness

Health Expertise

\section{Details}

Before first case reported: Travells Monitoring from China; Having Restriction for several places

Before and after first case reported: Setting up an emergency hospital; Rapidly Test; The government additionally made forceful move to guarantee satisfactory supplies of careful masks, including ventured up assembling, trade bans, price limits, and a constraint of one to nine covers for every buy; provide pathologists and clinical laboratory professionals, Taiwan has a world-class health care system, with universal coverage. Utilization technology through big data, cloud computing, and data integration; good communication and cooperation with other agencies; leadership matter.

Integration of mass media to educate people, giving important information about Covid19; understanding and mutual assistance; guarantee that any laws or regulations enacted in response to Covid-19 are for the authentic motivation behind ensuring general wellbeing, and that any limitations force are sensible, proportionate and carefully time bound.

Source: Author.

Table 1. Taiwan's Policies Strategy in Dealing with Covid-19 Outbreak.

Looking at the table above, if seen from the public policy theory of the Taiwan government in this case applying the concept of responsive policy to cases faced by the state. Indicators of success in handling Covid-19 launched by WHO which include country-level coordination, planning, and monitoring; risk communication and community engagement; surveillance, rapid-response teams, and case investigation; points of entry; national laboratories; infection prevention and control; case management; operations support and logistics in this case has been implemented well through policies produced by the Taiwan government. Therefore, with the alternative policies carried out by the Taiwan government that have been described, the country does not need a lockdown, so economic activity in Taiwan is still stable amid the Covid-19 
outbreak.The anticipation and control of Covid-19 requires joint endeavors by governments and residents. This emergency shows that pandemics couldn't care less about race or national fringes. Through worldwide plague data sharing and clinical participation, the effect of the Covid-19 pandemic can be limited. In the event that a nation can outperform the obstructions between ideological groups and ethnic gatherings and discharge scourge avoidance data with dynamic, convenient, and incorporated measures, it will have made a vital advance towards great administration the best alleviation measures for pandemic counteraction.

\section{CONCLUSION}

Taiwan government proved its success in fighting the Covid-19 outbreak independently, although it was not included in the world health organization. Responsive policies with a number of strategies have been implemented by the Taiwan government including through early awareness, health expertise, government competence, and popular alertness. Until this research was completed, Taiwan was stuck in 395 cases with a mortality rate of 6, implying that only 0.015 percent of the total cases. In addition, policy indicators made by WHO include country-level coordination, planning, and monitoring; risk communication and community engagement; surveillance, rapid-response teams, and case investigation; points of entry; national laboratories; infection prevention and control; case management; operations and logistics operations are in line with the strategic policies carried out by the Taiwan government.

\section{REFERENCE}

Cheng, S., Chang, Y., Chiang, Y. F., Chien, Y., Cheng, M., Yang, C., ... Hsu, Y. (2020). First case of Coronavirus Disease 2019 ( COVID-19) pneumonia in Taiwan. Journal of the Formosan Medical Association, 2019(1492), 0-4. https://doi.org/10.1016/j.jfma.2020.02.007

Control, T. C. for D. (2020). coronavirus disease 2019(COVID-19). Taiwan.

Creswell, J. W. (2010). Research design: pendekatan kualitatif, kuantitatif, dan mixed. Yogjakarta: PT Pustaka Pelajar.

Djalante, R., Shaw, R., \& Dewit, A. (2020). Progress in Disaster Science Building resilience against biological hazards and pandemics : COVID-19 and its implications for the Sendai Framework Progress in Disaster Science. Progress in Disaster Science, 6, 100080. https://doi.org/10.1016/j.pdisas.2020.100080

Embun, B. (2012, April 17). Banjir Embun. Retrieved from Penelitian Kepustakaan: http://banjirembun.blogspot.co.id/2012/04/penelitian-kepustakaan.html

Hevia, B. C., \& Neumeyer, A. (2020). UNDP LAC C19 PDS No . 1 A Conceptual Framework for Analyzing the Economic Impact of COVID-19 and its Policy Implications. (1), 1-18.

Huang, C., Wang, Y., Li, X., Ren, L., Zhao, J., Hu, Y., ... Gu, X. (2020). Articles Clinical features of patients infected with 2019 novel coronavirus in Wuhan, China. 497-506. https://doi.org/10.1016/S0140-6736(20)30183-5

Huang, W., Teng, L., Yeh, T., Chen, Y., Lo, W., Wu, M., ... Liu, P. (2020). ScienceDirect 2019 novel coronavirus disease ( COVID-19) in Taiwan : Reports of two cases from Wuhan ,. Journal of Microbiology, Immunology and Infection, (xxxx), 0-3. https://doi.org/10.1016/j.jmii.2020.02.009

Hui, M. (2020, April 1). How Taiwan is tracking 55,000 people under home quarantine in real time. Quartz.

Husnayain, A., Fuad, A., \& Su, E. C. (2020). Applications of google search trends for risk communication in infectious disease management: A case study of COVID-19 outbreak in Taiwan. International Journal of Infectious Diseases. https://doi.org/10.1016/j.ijid.2020.03.021 
International Labour Organization. (2020). What are the key policies that will mitigate the impacts of COVID-19 on the world of work? USA.

Jennifer, M. (2020). Characteristics of and Important Lessons From the Coronavirus Disease 2019 ( COVID-19) Outbreak in China Summary of a Report of 72314 Cases From the Chinese Center for Disease Control and Prevention. 323(13).

Jhang, S. S. \& R. (2020, March 16). Taiwan's Action Strategies Provide Great Model to Fight Coronavirus. Geneonline News.

John, P. (2018). New Directions in Public Policy: Theories of Policy Change and Variation Theories of policy change and variation reconsidered: a prospectus for the political economy of public policy *. (November). https://doi.org/10.2139/ssrn.2286711

https://www.brookings.edu/blog/techtank/2020/04/13/combating-covid-19-lessons-fromsouth-korea/

https://theconversation.com/why-singapores-coronavirus-response-worked-and-what-we-canall-learn-134024

https://healthmanagement.org/c/hospital/news/where-are-the-most-effective-anti-covid-19strategies

Kevin B. Smith \& Christopher W. Larimer. (2009). The Public Policy Theory Primer.

Lin, H.-M. (2020, April 2). Lessons from Taiwan's coronavirus response. East Asia Forum.

Mackay, M. (n.d.). What is Policy? What is Public Policy? Who Makes Public Policies? What is the Public Policy Cycle? Who is Involved in the Policy Cycle?

Mayr, V., Ai, D., Chapman, A., Persad, E., Klerings, I., Wagner, G., ... Zachariah, C. (2020). measures to control COVID-19 : a rapid review ( Review ). Cochrane Database of Systematic Reviews. https://doi.org/10.1002/14651858.CD013574.www.cochranelibrary.com

Nadeem, S. (2020). CORONAVIRUS COVID-19: AVAILABLE FREE LITERATURE PROVIDED BY VARIOUS COMPANIES , JOURNALS AND ORGANIZATIONS AROUND THE LITERATURE PROVIDED BY VARIOUS COMPANIES , JOURNALS AND ORGANIZATIONS AROUND THE WORLD. (March). https://doi.org/10.5281/zenodo.3722904

Nelson, C. W. (2020, March 10). COVID-19: don't ignore Taiwan. Nature.

Oni, E. O. (2019). Public policy analysis. (November 2016).

$\mathrm{Pu}, \mathrm{V}$. (Lin). (2020, February 27). The Coronavirus Outbreak: How Democratic Taiwan Outperformed Authoritarian China. The Diplomat.

Schafer, H. (2020, April 2). COVID-19 will hit South Asia hard. We are fighting back. Worl Bank.

Sui, C. (2020, March 10). What Taiwan can teach the world on fighting the coronavirus Analysis: Taiwan put lessons it learned during the 2003 SARS outbreak to good use, and this time its government and people were prepared. NBC News.

Taiwan Centers for Disease Control. (2020). Taiwan timely identifies first imported case of 2019 novel coronavirus infection returning from Wuhan, China through onboard quarantine; Central Epidemic Command Center (CECC) raises travel notice level for Wuhan, China to Level 3: Warning. Taiwan.

WHO. (2020a). Coronavirus disease 2019 (COVID-19). 2019(March).

WHO. (2020b). Critical preparedness, readiness and response actions for COVID-19. (March).

WHO. (2020c). OPERATIONAL PLANNING GUIDELINES TO SUPPORT COUNTRY PREPAREDNESS AND RESPONSE. USA.

Wu, Y., Chen, C., \& Chan, Y. (2019). The outbreak of COVID-19: An overview. 217-220. https://doi.org/10.1097/JCMA.0000000000000270>Wu

Yang, W. (2020, April 9). How has Taiwan kept its coronavirus infection rate so low? DW. 
Zed, M. (2014). Metode Penelitian Kepustakaan. Jakarta: Yayasan Obor Indonesia. 